\title{
Fuzzy interpolation of hydro power sales data in Simulink
}

\author{
Jantzen, Jan; Eliasson, B.
}

Published in:

Proceedings of the 3rd IEEE Conference on Fuzzy Systems

Link to article, DOI:

10.1109/FUZZY.1994.343576

Publication date:

1994

Document Version

Publisher's PDF, also known as Version of record

Link back to DTU Orbit

Citation (APA):

Jantzen, J., \& Eliasson, B. (1994). Fuzzy interpolation of hydro power sales data in Simulink. In Proceedings of the 3rd IEEE Conference on Fuzzy Systems (Vol. Volume 3, pp. 1857-1860). IEEE.

https://doi.org/10.1109/FUZZY.1994.343576

\section{General rights}

Copyright and moral rights for the publications made accessible in the public portal are retained by the authors and/or other copyright owners and it is a condition of accessing publications that users recognise and abide by the legal requirements associated with these rights.

- Users may download and print one copy of any publication from the public portal for the purpose of private study or research.

- You may not further distribute the material or use it for any profit-making activity or commercial gain

- You may freely distribute the URL identifying the publication in the public portal

If you believe that this document breaches copyright please contact us providing details, and we will remove access to the work immediately and investigate your claim. 


\title{
Fuzzy Interpolation Of Hydro Power Sales Data In Simulink
}

\author{
Jan Jantzen \\ Technical University of Denmark \\ Building 325, DK-2800 Lyngby, DENMARK \\ Bitnet/earn: stardust@vm.uni-c.dk \\ Bo Eliasson \\ Sydkraft AB \\ S-205 09, Malmo, SWEDEN
}

\begin{abstract}
The problem in this case study can be described as a multi-dimensional surface fit to a given set of data. The data are sales figures in $M W H / H$ for a hydro-thermal power generation system. The data are incomplete and not totally reliable. A model with ten fuzzy rules fits the data with a total error of $19 \%$; with twentysix rules the error would be $0 \%$. The model is used in the long term planning concerning operating costs. It is further intended as a short term decision support for operators when negotiating power interchange contracts.
\end{abstract}

\section{INTRODUCTION}

Before the high load season the water reservoirs in the Nordic countries for power generation are usually full. From winter to spring the water level gradually sinks to a minimum of, say, $15 \%$ to $30 \%$. When the snow in the mountains melt, the spring flood sets in, and the water rises to its peak level sometime in the autumn. There are two main goals of water reservoir management: 1) to prevent the reservoirs from drying out prior to the spring flood, and 2) to fill the reservoirs in the autumn without spilling water. Excess water, especially in a "wet year" with plenty of rain or snow storage, may be converted to power at virtually no cost except taxes and sold to other power companies, neighbouring countries, or, in the near future, on a European "power exchange".

The energy stored in reservoirs is measured frequently statistics for Norway, Finland and Sweden, for instance, are published quarterly - and the purpose of a model is to predict the amount of power for sale depending on variables like storage and precipitation. Such a prediction is especially useful in the long term planning of how to operate generating units (nuclear, fossil, gas, hydro, purchase) in order to meet the predicted consumer load ("unit commitment").

A local expert has supplied typical sales figures based on historical data and subjective judgment. The estimated sales figures depend on reservoir level (measured in percentages of full scale), month of the year, rain- and snowfall (in percentages above or below normal precipitation), and home power consumption (in $\mathrm{MWH} / \mathrm{H}$ above or below normal). The estimates are precise numbers, but incomplete and not totally reliable.

To build a model the most straight forward way would be to use linear interpolation. The estimates could be placed in an array and missing elements filled in. The array would be multi-dimensional, and the interpolation procedure would be accordingly complex. A second possibility would be statistical or model identification methods, hoping to find some sort of correlation between the input and output variables. A third possibility would be a mathematical model based on first principles and problem insight. A fourth possibility might be to feed historical data into a neural network, and have it identify the relationship between the five variables.

The multivariable problem and the incompleteness of the data motivated a fuzzy rule-based model. The other possibilities mentioned above have not been investigated since we were looking for a demonstration problem for fuzzy logic. For maximal end-user control of the design phase, a prototyping approach was adopted using the simulation environment Simulink (Mathworks, 1993).

\section{INTERPOLATION MODEL}

Fuzzy rules are appropriate in a number of cases within the problem area. One case is in the evaluation of the home power consumption compared to normal. An example of a set of rules is

If consumption is above normal then sell $100 \mathrm{MWH} / \mathrm{H}$ less If consumption is below normal then sell $100 \mathrm{MWH} / \mathrm{H}$ more

The shape of the fuzzy membership functions, related to the fuzzy terms in italics, directly determine each rule's contribution to the sales measured in mega-watt-hours per 
hour $(\mathrm{MWH} / \mathrm{H})$. In a conventional program, the relationship between consumption on the one hand and sales on the other would probably be implemented as a piece-wise linear table function with interpolation. The major advantage of using fuzzy rules here is the rule format which is usually considered more user-friendly.

Another case is in the evaluation of the hydro for sale depending on water level and the time to spring flood:

If level is above reference and time to spring flood is large then sales are $200 \mathrm{MWH} / \mathrm{H}$

If level is above reference and time to spring flood is small then sales are $800 \mathrm{MWH} / \mathrm{H}$

In this case there are two input variables to the rule block: level and time to spring flood. There is one output variable: sales. A fuzzy program will handle all possible combinations of input data and interpolate the sales between 0 and 800 $\mathrm{MWH} / \mathrm{H}$. This multivariable relationship is much harder to implement in a non-fuzzy program.

A third case is in the evaluation of the rain- and snowfall (precipitation). Several decisions depend on whether it is a wet year with up to $15 \%$ more precipitation than usual, or not. The accumulated energy in the snow is a good indicator for wet and dry years. The rainfall is generally estimated.

The model is a four-input-one-output system. It contains eight rather similar rules and a rule block which takes care of the home power consumption (1). The latter relationship is simple because it is independent of the three other inputs, and the outcome is just added to the sales (Fig. 1). The rule block is named "Rules2", and it can be opened for further study by double clicking on the block (Fig. 2).

The rest of the model concerns the rather complex relationship between month, level, precipitation and sales. The overall design principle is that the relationship is mainly determined by eight characteristic cases (TABLE I). Each case holds original sales data for a combination of month and precipitation. The model is able to interpolate between the eight cases in the 'solution space', because the rules are fuzzy.

To be specific, the model assumes that the sales in January, May, June, and December are characteristic; the rest of the year is modelled as a blend of these, two-by-two. January is characteristic because sales are low here. This is probably due to fear of drying out the reservoir before the spring flood sets in. May is characteristic, because sales are rather high. This is because the spring flood is very close, and the risk of drying out is small. June is also characteristic, because sales are very reluctant, partly due to the risk of not filling the reservoir, partly due to government regulations conceming the environment. December is characteristic because sales are very high; this is probably due to fear of spilling water.

The eight rules of the model are specified in a compact manner in TABLE 1. Each column represents a variable and each row a rule. In the familiar if-then format the first rule, for instance, would read:

If the month is January and it is not a wet year then sales would be [some number depending on level]

TABLE I

SALRS STRATEOY

\begin{tabular}{llrrr}
\hline MONTH & WET & \multicolumn{3}{c}{ LEVEL $[8]$} \\
& & SALES $[$ MWH $/ \mathrm{H}]$ \\
\hline Jan & No & 70 & 75 & 85 \\
& & 0 & 210 & 200 \\
Jan & Yes & 75 & 85 & \\
& & 400 & 600 & \\
May & No & 35 & 40 & 55 \\
& & 0 & 300 & 900 \\
May & Yes & 35 & 40 & \\
& & 225 & 500 & \\
Jun & No & 40 & 60 & 70 \\
& & 0 & 100 & 900 \\
Jun & Yes & 40 & 60 & \\
& & 100 & 500 & \\
Dec & No & 80 & 85 & 90 \\
& & 0 & 250 & 800 \\
Dec & Yes & 80 & 85 & 90 \\
& & 200 & 300 & 900 \\
\hline
\end{tabular}

The variables MONTH and WET (year) are regarded as independent, and SALES as the dependent variable. The sales are assumed linearly dependent on level.

The resultant sales value is computed in a manner similar to the inference in a fuzzy controller (see, e.g., [1]), only slightly modified. The contribution of each rule is computed as

$$
\begin{aligned}
& \operatorname{JAN}(t) \text { AND NOT WET }(p)=w_{1} \\
& \operatorname{JAN}(t) \text { AND WET }(p)=w_{2} \\
& \operatorname{MAY}(t) \text { AND NOT WET }(p)=w_{3} \\
& \ldots
\end{aligned}
$$

Here $t$ is the time of year, $p$ is the precipitation, and the $w_{\mathrm{i}}$ 's are the weights, or firing strengths, of the rules. The sales number $s_{i}$ from the $i$ th rule is

$$
s_{\mathbf{i}}=\mathbf{f}_{\mathbf{i}}(\text { level })
$$

where $f_{i}$ is a linear interpolation function using the $i$ th interpolation table in the right column of TABLE I. The 
resulting sales number $s$ is the weighted average of all contributions, i.e.,

$$
s=\left(\Sigma w_{\mathrm{i}} s_{\mathrm{i}}\right) / \Sigma w_{\mathrm{i}}
$$

For example, if the input is $t=1$ for january and $p=0 \%$, then the first rule will contribute, but none of the others will. The values of the MONTH variable are defined as

$$
\begin{aligned}
& \text { jan }=10.80 .50 .300000000 \\
& \operatorname{may}=00.20 .50 .710000000 \\
& \text { jun }=00000010.90 .50 .40 .200 \\
& \mathrm{dec}=0 \begin{array}{llllllllll}
0 & 0 & 0 & 0 & 0 & 0.10 .50 .60 .811
\end{array}
\end{aligned}
$$

If $t=3$ for March and $p=10 \%$, more rules will contribute: Since the month is neither January nor May the model decides that it is January to the degree 0.5 and May to the degree 0.5 . Similarly, it is a wet year in the degree 0.75 and not a wet year in the degree 0.25 . In fact, all of rules $1-4$ will contribute. The fuzzy membership curves for the MONTH variable have been handtuned to get the best fit to the original data, more or less. The membership curve for WET is a standard s-curve.

In the "Rules1" block, the input level is immediately compared to a reference curve on which the sales are zero (Fig. 3). Instead of using the absolute level the model computes the surplus relative to the reference curve, a number between 0 and $30 \%$, and uses this in further calculations. This is a normalisation that makes it easier to compare and interpolate sales in different months.

Some of the fuzzy membership values are being combined using fuzzy operations. These have been implemented as blocks (for example AND, OR, NOT) using the Simulink facilities. All fuzzy blocks are collected in a library (Fig. 4). The first row of blocks are various ways to implement fuzzy sets. The blocks have generic names like 's-curve', 'pi-curve', etc. to make them general. The names are easily changed into, say, 'low' and 'ok' by clicking on the names (not the block). The middle row of blocks concerns operations on sets. The common set operations 'and', 'or', 'not' are implemented quite easily in Simulink. For completeness the modifiers 'very' and 'rather' have been included. The last row contains some auxiliary functions that the model uses. They are not fuzzy operations, but necessary functions that did not exist in the standard Simulink library.

\section{TEST RESULTS AND Discussion}

Since the problem at hand is essentially a data fitting problem, it is possible to evaluate the accuracy by comparing the model's output against the original data. These are conveniently arranged in two matrices: one for a normal year and one for a wet year. Since they are incomplete there are a lot of empty cells.

The non-empty cells have been compared with the model's output. Summing all differences numerically, the model is off by a total error of $19 \%$. The average error for each of the 55 non-empty cells is $67 \mathrm{MWH} / \mathrm{H}$.

This result could perhaps be improved by optimizing the fuzzy membership curves, but probably only slightly. It will definitely help to increase the number of rules instead. The extreme case of $2 \times 12$ rules, one for each month in the wet / normal cases, plus the two rules for home consumption (1) will result in $0 \%$ error.

To get a picture of how the interpolation performs, Fig. 5 is a plot of an interpolated curve against some tabulated points. The plot concerns a fixed surplus of water (10\% over the reference), a fixed precipitation ( $0 \%$ precipitation over normal), and a fixed home consumption ( $0 \%$ of normal), so the sales vary with the time of the year only. The plot shows that the interpolation is anchored in the values for January, May, June and December. The values in between are determined by the blending of two neighbouring anchor point values with a blending ratio governed by the fuzzy membership functions.

The model is fairly easy to use because of the graphical layout. Nevertheless, unskilled users have to be trained somewhat in Simulink and perhaps also Matlab. Basic knowledge of fuzzy sets is necessary also.

Some useful extensions are possible, including

- a dynamic model of the reservoirs including alternative regulation policies;

integration with optimization programs (unit commitment, power flow).

Knowledge based decision systems for operators, e.g., voltage collapse constraints, monitoring of certain cut sets, are multiinput systems where the fuzzy techniques are of interest. The model is also useful for teaching purposes.

\section{CONCLUSION}

The case study shows that it is rather easy to model the complex relationship between the sales numbers and the four independent variable. The accuracy of the fit depends on the number of rules. Since a conventional linear interpolation program would provide a fit with zero error, the benefit of the fuzzy solution is not in the performance, but in the rule-based structure: it is user-friendly, and it is easy to add new rules even new variables are quite easy to add. 


\section{ACKNOWLEDGEMENT}

Marten Eriksson, Sydkraft, has supplied the data (although they have been changed for publication) and expert knowledge. His insight and participation is gratefully appreciated.

\section{REFERENCES}

D. Driankov, H. Hellendoom, and M. Reinfrank, An Introduction To Fuzzy Control. Berlin: Springer-Verlag, 1993.

Mathworks, Simulink User's Guide. The Mathworks, Inc., Cochituate Place, 24 Prime Park Way, Natick, MA 01760, USA, 1993.

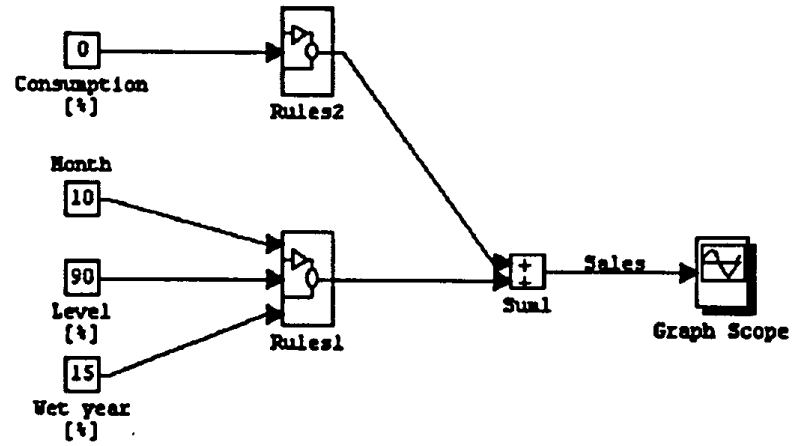

Fig. 1. Overall atructure of the interpolation model.

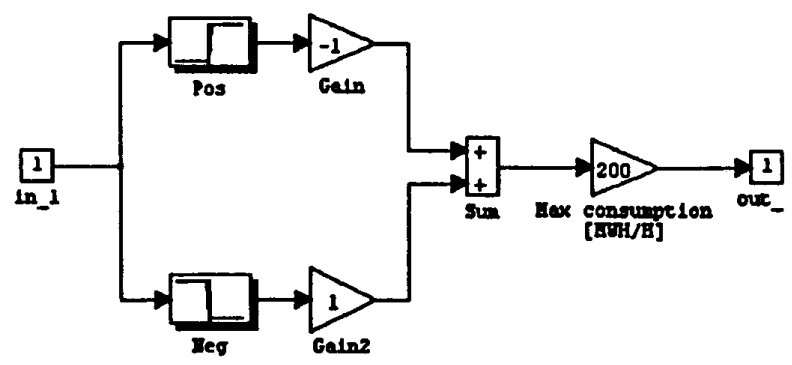

Fig. 2. Contents of the "Rules2" block conceming home consumption.

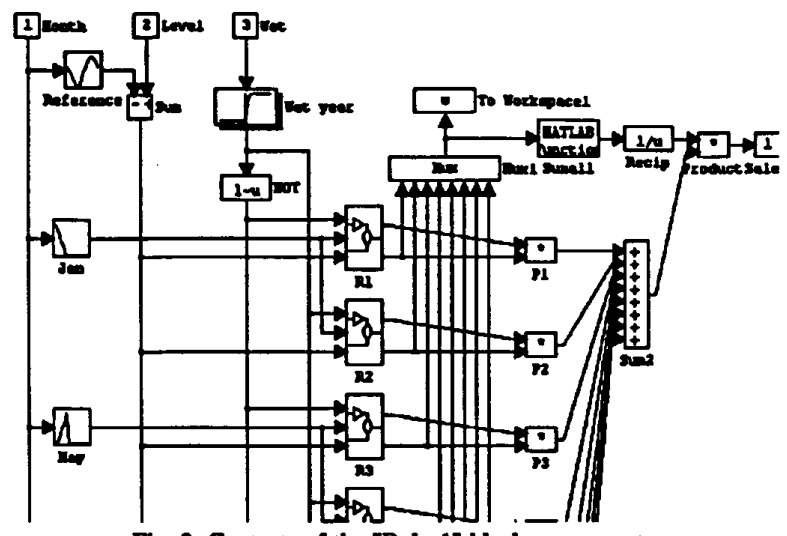

Fig. 3. Contents of the "Rules1" block, upper part.

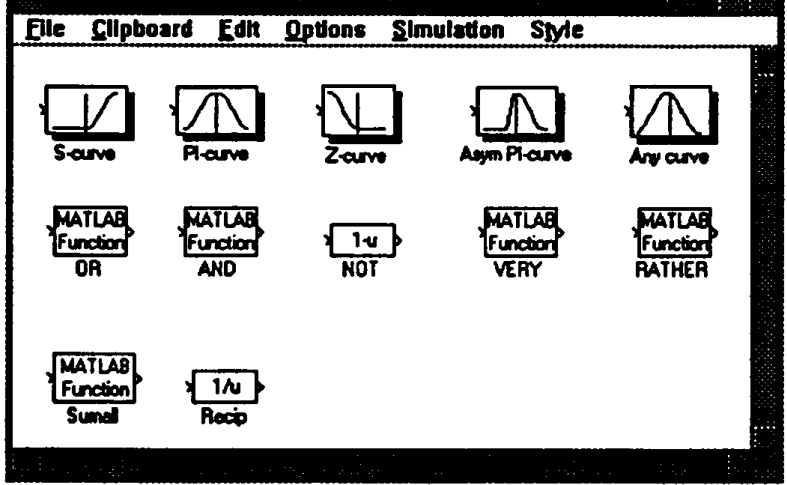

Fig. 4. Library of fuzzy blocks.

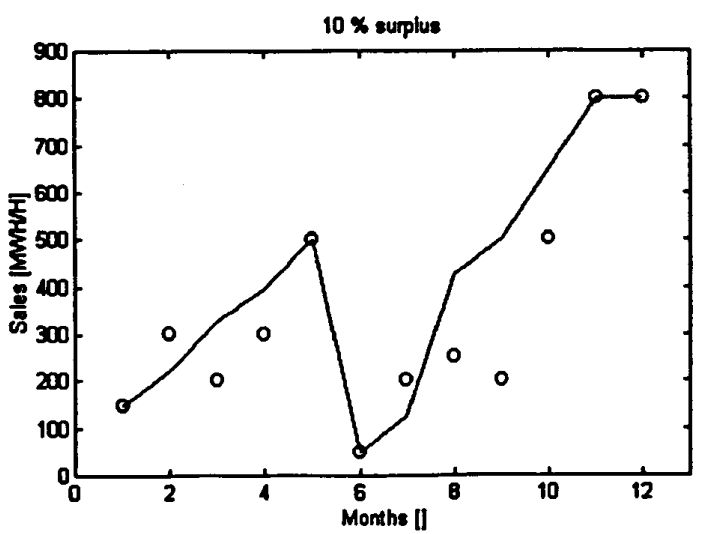

Fig. 5. Interpolated sales curve compared to tabulated points (circles). 